\title{
Prevalence of acute toxoplasmosis infection among 41,112 pregnant women and the mother-to-child transmission rate in a public hospital in South Brazil
}

\author{
Ivana S Varella ${ }^{1}{ }^{+}$, Ivete CT Canti ${ }^{1}$, Breno R Santos ${ }^{1}$, Angela Z Coppini ${ }^{1}$, Luciana C Argondizzo ${ }^{1}$, \\ Carina Tonin', Mário B Wagner ${ }^{2}$
}

${ }^{1}$ Hospital Nossa Senhora da Conceição, Grupo Hospitalar Conceição, Porto Alegre, RS, Brasil ²Programa de Pós-Graduação em Epidemiologia, Universidade Federal do Rio Grande do Sul, Porto Alegre, RS, Brasil

Untreated acute toxoplasmosis among pregnant women can lead to serious sequelae among newborns, including neurological impairment and blindness. In Brazil, the risk of congenital toxoplasmosis (CTox) has not been fully evaluated. Our aim was to evaluate trends in acute toxoplasmosis prevalence from 1998-2005, the incidence of CTox and the rate of mother-to-child transmission (MTCT). A cross-sectional study was undertaken to dentify patients who fit the criteria for acute toxoplasmosis during pregnancy. Exposed newborns were included in a historical cohort, with a median follow-up time of 11 months, to establish definite diagnosis of CTox. Diagnoses for acute infection in pregnancy and CTox were based on European Research Network on Congenital Toxoplasmosis criteria. In 41,112 pregnant women, the prevalence of acute toxoplasmosis was 4.8/1,000 women. The birth prevalence of CTox was 0.6/1,000 newborns [95\% confidence interval (CI): 0.4-0.9]. During the follow-up study, 12 additional cases were detected, increasing the CTox rate to 0.9/1,000 newborns (95\% CI: 0.6-1.3). Among the 200 newborns exposed to Toxoplasma gondii, there were 37 babies presenting diagnostic criteria of CTox, leading to an MTCT rate of $18.5 \%$ (95\% CI: 13.4-24.6\%). The additional cases identified during follow-up reinforce the need for serological monitoring during the first year of life, even in the absence of evidence of congenital infection at birth.

Key words: toxoplasmosis - congenital toxoplasmosis - pregnancy

Untreated acute toxoplasmosis among pregnant women can lead to infection of the foetus via transplacental transmission. Although newborns affected by congenital infection may seem normal upon first examination, serious sequelae, such as neurological impairment and blindness, can develop a few years later (Mombro et al. 1995, Dunn et al. 1999, Safadi et al. 2003, Remington et al. 2005).

In high risk areas, serological screening has been recommended to identify susceptible individuals in order to adopt primary preventive measures (Foulon et al. 1988). Some reports have suggested that pregnant women diagnosed with acute toxoplasmosis should be treated as soon as possible to reduce the risk and severity of congenital infection (Foulon et al. 1999, Gilbert et al. 2001, Gras et al. 2005). Others have argued that there is still no treatment capable of reducing vertical transmission (Foulon et al. 2000, Peyron et al. 2000, Gilbert et al. 2001). Nevertheless, a recent meta-analysis reported that a maternal treatment started within three weeks of seroconversion had a small effect in the reduction of vertical transmission when compared to treatments that were started eight or more weeks after seroconversion (Thiebaut et al. 2007).

\footnotetext{
+ Corresponding author: ivana.varella@gmail.com

Received 10 October 2008

Accepted 24 March 2009
}

Incidence studies of acute toxoplasmosis around the world have found rates per 1,000 pregnancies of 0.5 in Sweden (Evengard et al. 2001), 1.7 in Norway (Jenum et al. 1998), 2.1 in Denmark (Lebech et al. 1999), 2.0 in New York, USA (Lopez et al. 2000), 6.6 in Paris, France (Remington et al. 2005), and 8.5 in Belgium (Naessens 2003). In Brazil, there is no established epidemiological surveillance program for toxoplasmosis among pregnant women. Despite that, the prevalence of acute toxoplasmosis per 1,000 pregnant women in Mato Grosso do Sul was 4.2 (Figueiro-Filho et al. 2007) and 5.7 in Brasilia (Nobrega \& Karnikowski 2005).

The occurrence of congenital toxoplasmosis (CTox) was found to be $0.07 / 1,000$ births in Sweden (Evengard et al. 2001), 0.08/1,000 in Massachusetts, USA, and in London, England (Guerina et al. 1994, Gilbert et al. 1995), 0.12/1,000 in Switzerland (Signorell et al. 2006), 0.3/1,000 in Barcelona, Spain (Munoz Batet et al. 2004), $0.4 / 1,000$ in Denmark (Lebech et al. 1999), 1.1/1,000 in Poland (Paul et al. 2001), and 1.9-3.2/1,000 in Paris, France (Remington et al. 2005).

In Brazil, the occurrence of CTox varied according to study design and serological method. In the Southern region, the prevalence of congenital infection based on cord blood samples reached $0.8 / 1,000$ births $(95 \%$ CI: 0.02-4.45) (Mozzatto \& Procianoy 2003). Other studies using blood samples adsorbed onto filter paper found prevalences from $0.3 / 1,000$ (Neto et al. 2000) to $0.6 / 1,000$ newborns (Lago et al. 2007). In Ribeirão Preto, São Paulo, another cross-sectional study also using blood samples adsorbed onto filter paper (Carvalheiro et 
al. 2005) found a prevalence of $0.3 / 1,000$ births. Using cord blood samples, Segundo et al. (2004) found a high prevalence of 5.0/1,000 newborns (95\% CI: $1.4-12.7)$ in Uberlândia, Minas Gerais.

Mother-to-child transmission (MTCT) rates have been found to be around 20-50\% (Jones et al. 2001). Several studies have suggested lower rates of foetal transmission when maternal infection took place early during gestation (Hohlfeld et al. 1989, Jenum et al. 1998, Dunn et al. 1999, Foulon et al. 1999, Remington et al. 2005). On the other hand, there are reports that point towards a more serious disease when the mother is infected during the first trimester (Hohlfeld et al. 1989, Dunn et al. 1999, Montoya \& Liesenfeld 2004). Apparently, these two findings are contradictory and need further investigation.

Considering the above points, we decided to conduct a study to estimate the prevalence of acute toxoplasmosis among pregnant women in a large public hospital in Southern Brazil. Additionally, we estimated the birth prevalence of CTox and its incidence during the first year of life. We also assessed MTCT rates based on the likeliness of infection as determined by the diagnostic categories set by the European Research Network on Congenital Toxoplasmosis (ERNCT).

\section{PATIENTS, MATERIALS AND METHODS}

Patients - Maternity care at Hospital Nossa Senhora da Conceição (HNSC), a 900-bed public general hospital in Porto Alegre, Rio Grande do Sul, Brazil, is characterised by assisting medium and high risk pregnancies covered by the Brazilian National Health System. The hospital is a reference centre for assisting pregnant women and babies with suspected or proven Toxoplasma gondii infections. A cross-sectional study was conducted from October 1998-December 2005 in which 41,112 pregnant women were screened for $T$. gondii antibodies. All of the newborns from the women presenting ERNCT diagnostic criteria (Lebech et al. 1996) of acute toxoplasmosis during pregnancy were included in a historical cohort. The infants were included in a follow-up study for a median time of 11 months to identify definite diagnosis by persistent $\operatorname{IgG}$ antibodies.

The diagnostic criteria used in this study were based on an adaptation of the ERNCT classification system due to the inclusion of the IgG avidity test in our routine. Therefore, the probability of a primary T. gondii infection during pregnancy was grouped into four categories: definite, probable, possible and unlikely. In addition to the maternal criteria diagnosis, we considered a positive polymerase chain reaction (PCR) nested assay in the amniotic fluid as a definite diagnosis, while a low $\operatorname{IgG}$ avidity test was considered a probable diagnosis. The newborns were screened soon after birth using clinical examination, complete blood cell count with differential and platelet count, specific anti-T. gondii $\mathrm{IgG}$ and IgM antibodies, cerebrospinal fluid (CSF) cell count, head ultrasonographic evaluation, PCR-nested assays of blood or CSF samples and a detailed ophthalmologic examination. All positive specific-IgM antibody results were re-tested on the fifth or sixth day of life. Additionally, in the neonatal evaluation, we considered a blood sample or CSF with a positive PCR-nested assay as a probable diagnosis. These assays were not part of the original ERNCT criteria (Lebech et al. 1996). Unlikely cases were not included when CTox rates were calculated. Pregnant women with positive $\operatorname{IgM}$ and persistently low IgG concentrations (lower than $300 \mathrm{UI} / \mathrm{mL}$ ) were excluded if the initial serology was performed during the first 20 weeks of pregnancy. This serological profile with a residual IgM index suggests an infection prior to the pregnancy. HIV-positive women and those with high $\mathrm{IgG}$ avidity detected in the first 16 weeks of pregnancy were also excluded (Remington et al. 2005).

Materials - Three different immunological assays were used in the serological survey. During the first four years, the Microparticle Enzyme Immunoassay (MEIA, Abbott Diagnostics AxSYM ${ }^{\circledR}$ SYSTEM Toxo IgG and IgM version 2.0) was used alone. Since 2001, the hospital has introduced two additional tests to confirm MEIA's results: IgM capture technique and $\operatorname{IgG}$ avidity by Enzyme Linked Fluorescent Assay (VIDAS ${ }^{\circledR}$ ).

Statistical analysis - Proportions and their respective $95 \%$ confidence intervals were calculated based on the binomial distribution. The chi-square procedure was used to assess linear trends among proportions during the study period.

Ethics - The present work has been approved by the ethics committee of HNSC.

\section{RESULTS}

From October 1998-December 2005, 41,112 pregnant women sought assistance at the HNSC's maternity health facility. The distribution of 241 of the initially included pregnant women is presented in Table I, according to ERNCT categories (definite, probable, possible and unlikely diagnosis). Among these women, 199 were identified using ERNCT criteria (definite, probable or possible) to have acute toxoplasmosis, which led to a cumulative prevalence of $4.8 / 1,000$ pregnancies $(95 \% \mathrm{CI}$ : 4.2-5.6). Due to a twin gestation, there were 200 exposed babies included in the follow-up study.

Figure shows acute toxoplasmosis prevalence rates in pregnant women during the study. After 2001, there was a considerable decrease in the prevalence rates from $6.6 / 1,000$ (in 2001) to $2.1 / 1,000$ pregnancies (in 2005) $\left(\chi^{2}\right.$ for trend, $\mathrm{p}<0.001)$.

After 2001, the proportion of women with systematic serological screening performed during antenatal care was higher than in the previous period $(86.7 \%$ vs. $64.1 \%$, respectively). However, when IgM capture and IgG avidity tests were introduced in our routine, it was observed that the average gestational age for testing during pregnancy became progressively higher (27.3-32.1 weeks from 2002-2005).

There were 40,727 live births out of the 41,112 pregnancies. Out of these, 25 were considered to have CTox at birth. When only considering the definite and probable categories, the estimated prevalence of CTox at birth was 0.6/1,000 newborns (95\% CI: 0.4-0.9). Twelve 


\section{TABLE I}

Cumulative prevalence of acute toxoplasmosis infection in pregnant women according to ERNCT classification system and case definition of Toxoplasma gondii infection in immunocompetent pregnant women $(\mathrm{n}=241)$

\begin{tabular}{|c|c|c|c|}
\hline $\begin{array}{l}\text { Diagnostic category and criteria for the } \\
\text { diagnosis of primary infection during pregnancy }\end{array}$ & $\mathrm{n}$ & $\begin{array}{l}\text { Cumulative prevalence of } \\
\text { acute toxoplasmosis }{ }^{a}(/ 1.000)\end{array}$ & $95 \% \mathrm{CI}$ \\
\hline $\begin{array}{l}\text { Definite diagnosis } \\
\text { Serological conversion } \\
\text { Infected newborn }\end{array}$ & 43 & 1.0 & $0.7-1.4$ \\
\hline $\begin{array}{l}\text { Probable diagnosis } \\
\text { IgG greater than } 300 \mathrm{UI} / \mathrm{mL}^{c} \\
\text { Low IgG avidity } \\
\text { Maternal IgG increasing three or more times }{ }^{c}\end{array}$ & 72 & 2.8 & $2.3-3.3$ \\
\hline $\begin{array}{l}\text { Possible diagnosis } \\
\text { Equivocal IgG avidity after } 20 \text { weeks of gestation }{ }^{c} \\
\text { IgG less than } 300 \mathrm{UI} / \mathrm{mL} \text { and only single serum sample } \\
\text { at the moment of delivery }{ }^{c} \\
\text { IgG less than a } 300 \mathrm{UI} / \mathrm{mL} \text { and only single serum sample } \\
\text { during the prenatal period, after } 20 \text { weeks of gestation }{ }^{c}\end{array}$ & 84 & 4.8 & $4.2-5.5$ \\
\hline $\begin{array}{l}\text { Unlikely diagnosis } \\
\text { IgG lower than } 300 \mathrm{UI} / \mathrm{mL} \text { and high IgG avidity } \\
\text { with gestational time higher than } 16 \text { weeks }^{c} \\
\text { Stable IgG with exams performed after } 20 \\
\text { weeks of pregnancy }\end{array}$ & 42 & 5.9 & $5.2-6.6$ \\
\hline
\end{tabular}

additional cases were detected during the follow-up study, increasing the CTox rate to $0.9 / 1,000$ newborns (95\% CI: 0.6-1.3). Therefore, the incidence of CTox diagnosed during the first year of life was $0.3 / 1,000$ newborns (95\% CI: 0.2-0.5).

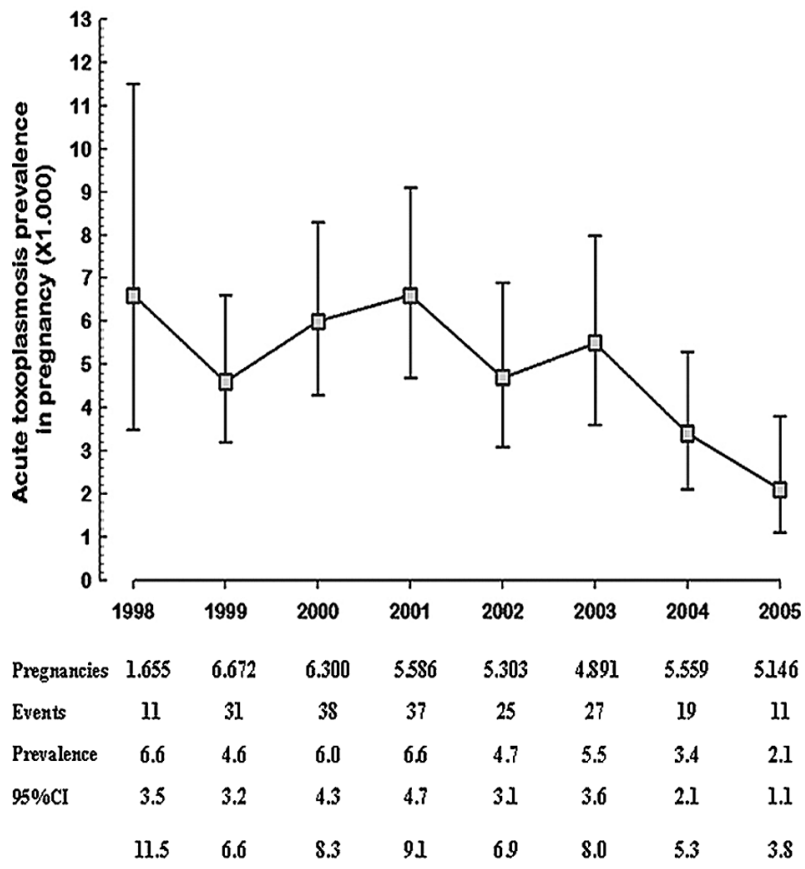

Acute toxoplasmosis prevalence in pregnant women between 19982005.
From the 200 exposed babies, we found 37 CTox cases according to ERNCT criteria by the end of the first year of life. This led to a MTCT rate of $18.5 \%(95 \% \mathrm{CI}$ : 13.5-24.7). The MTCT rates stratified by ERNCT categories for diagnosis of primary maternal infection are shown in Table II.

Because of losses during the follow-up period, it was not possible to establish a definite CTox diagnosis for 47 out of the 200 followed infants $(23.5 \%)$. Considering that both cohort groups had the same characteristics (origin, number of years of school and maternal age, prenatal care, amniocentesis, treatment during the pregnancy and birthweight), the losses probably did not influence the results.

\section{DISCUSSION}

The high prevalence of acute toxoplasmosis during pregnancy found in this study was expected, since a high frequency of seropositivity (prevalence: 59.8\%; 95\% CI: $57.0-62.5 \%$ ) in this population was reported in a previous study (Varella et al. 2003).

In the present report, we have stratified toxoplasmosis diagnosis according to adapted ERNCT criteria. Cases of acute acquired toxoplasmosis during gestation that were classified as definite or probable were responsible for our findings of an MTCT rate of $18.5 \%$, while the remaining categories, possible and unlikely, did not cause congenital infection.

The acute toxoplasmosis rate in pregnant women $(2.8 / 1,000)$ (Table I) found in this study was higher than the rates found in Sweden $(0.5 / 1,000)$ (Evengard et al. 2001), Norway (1.7/1,000) (Jenum et al. 1998), Denmark 
TABLE II

MTCT rate of toxoplasmosis by category and criteria for diagnosis of primary infection of the pregnant woman (n=199)

\begin{tabular}{|c|c|c|c|}
\hline $\begin{array}{l}\text { Diagnostic category and criteria for diagnosis } \\
\text { of primary infection during gestation }\end{array}$ & $\begin{array}{l}\text { n of infected } \\
\text { newborn }\end{array}$ & $\begin{array}{l}\text { MTCT } \\
\text { rate }(\%)\end{array}$ & $95 \% \mathrm{CI}$ \\
\hline $\begin{array}{l}\text { Definite }(\mathrm{n}=43) \\
\text { Serological conversion } \\
\text { Infected newborn }^{a}\end{array}$ & 35 & 81.4 & $66.6-91.6$ \\
\hline $\begin{array}{l}\text { Probable }(\mathrm{n}=72) \\
\text { IgG greater than } 300 \mathrm{UI} / \mathrm{mL}^{b} \\
\text { Low IgG avidity } \\
\text { Maternal IgG increasing three or more times }{ }^{b}\end{array}$ & 2 & 2.8 & $0.3-9.7$ \\
\hline $\begin{array}{l}\text { Possible }(\mathrm{n}=84) \\
\text { Equivocal IgG avidity after } 20 \text { weeks of gestation }{ }^{b} \\
\text { IgG less than } 300 \mathrm{UI} / \mathrm{mL} \text { and only single serum sample } \\
\text { at the moment of delivery } \\
\text { IgG less than a } 300 \mathrm{UI} / \mathrm{mL} \text { and only single serum sample } \\
\text { during the prenatal period, after } 20 \text { weeks of gestation }\end{array}$ & 0 & - & - \\
\hline
\end{tabular}

$a$ : included 1 fetal infection case according to a positive PCR of amniotic fluid; $b$ : results associated to the presence of reactive T. gondii-specific IgM; MTCT: mother-to-child transmission.

$(2.1 / 1,000)$ (Lebech et al. 1999) and New York $(2.0 / 1,000)$ (Lopez et al. 2000), but lower than the rates published by others (Naessens 2003, Remington et al. 2005).

In Brazil, the Southern region, where this study was conducted, has a low prevalence of toxoplasmosis among pregnant women (Nobrega \& Karnikowski 2005, Figueiro-Filho et al. 2007). However, there is substantial variability in the reported data, depending on chosen population, diagnostic methods used in screening, or even the different risk factors involved in disease transmission (Buffolano et al. 1996, Kapperud et al. 1996, Cook et al. 2000, Jones et al. 2001).

The introduction of the IgG avidity test in the diagnostic panel of acute toxoplasmosis reduced false-positive rates and unnecessary diagnostic and therapeutic interventions (Liesenfeld et al. 2001, Montoya et al. 2002, Remington et al. 2004).

We found that the IgG avidity test did not impact incidence rate findings in this study. This test can only rule out acute infection if performed within 16 weeks of gestation, contrary to what happened in our cohort (Remington et al. 2004). It seems that other factors may be involved in the reduction of toxoplasmosis prevalence. We considered that the reduction of prevalence during the study period could reflect a failure of the healthcare system in following guidelines and guaranteeing that the suspected case will have easy access to reference services. Additionally, the introduction of the IgM capture test may have contributed to the reduced prevalence due to its higher specificity, but this possibility was not evaluated in the present study.

The prevalence of CTox by the end of the first year of life in our study (0.9/1,000 newborns) was comparable to that found at birth in other areas of Southern Brazil (Glasner et al. 1992, Mozzatto \& Procianoy 2003, Lago et al. 2007). A prevalence of 5.0/1,000 newborns reported in Minas Gerais, Brazil, could partially be explained by the use of cord blood samples (Segundo et al. 2004). According to some authors, using this type of sample could induce higher false positive rates (Naessens et al. 1999).

Compared to other countries, our CTox rate at one year of age was similar to that found in Poland $(1.1 / 1,000)$ (Paul et al. 2001) and was greater than those reported for Sweden $(0.07 / 1,000)$ (Evengard et al. 2001), Massachusetts, USA $(0.08 / 1000)$ (Guerina et al. 1994) and London, England (0.08/1,000) (Gilbert et al. 1995), Switzerland $(0.12 / 1,000)$ (Signorell et al. 2006), Barcelona, Spain $(0.3 / 1,000)$ (Munoz Batet et al. 2004) and Denmark (0.4/1,000) (Lebech et al. 1999). Only in Paris, France was a higher occurrence reported (1.9-3.2/1,000) (Remington et al. 2005).

The high prevalence of CTox at 12 months of age found in our study $(0.9 / 1,000$ newborns) is cause for concern. This rate could have been underestimated, particularly if we take into account that some potential cases could have been lost in the follow-up study. On the other hand, some cases could have been added to our cohort due to referral bias. Therefore, we suggest future, large collaborative studies using a standardised methodology to gather more precise estimates of the burden of this disease in our region.

We found an overall rate for MTCT of $18.5 \%$. Due to the difficulties involved in establishing an adequate diagnosis during pregnancy, we presented MTCT rates by ERNCT categories. This approach encompasses all aspects of CTox and provides MTCT rates that could be compared between locations with different health systems. If we only consider the definite category, our MTCT rate could be as high as $81.4 \%$, which would be 
higher than that reported by Foulon et al. (1999). On the other hand, we should not neglect the possibility of transmission in the probable ERNCT category.

In Brazil, preventive strategies for CTox have not yet been proposed. There is some controversy regarding which screening method would achieve the best results. Should we perform antenatal screening with early treatment (Thiebaut et al. 2007) or neonatal screening and treat the consequences? Regarding these questions, our study has clarified one particular point: there is a considerable level of incidence, estimated to be around 0.3 cases $/ 1,000$ newborns, that goes undetected with the current neonatal screening strategy. The future challenge for CTox screening is to identify the most cost-effective strategy so that it may be adopted in the coming years.

\section{REFERENCES}

Buffolano W, Gilbert RE, Holland FJ, Fratta D, Palumbo F, Ades AE 1996. Risk factors for recent Toxoplasma infection in pregnant women in Naples. Epidemiol Infect 116: 347-351.

Carvalheiro CG, Mussi-Pinhata MM, Yamamoto AY, De Souza CB, Maciel LM 2005. Incidence of congenital toxoplasmosis estimated by neonatal screening: relevance of diagnostic confirmation in asymptomatic newborn infants. Epidemiol Infect 133: 485-491.

Cook AJ, Gilbert RE, Buffolano W, Zufferey J, Petersen E, Jenum PA, Foulon W, Semprini AE, Dunn DT 2000. Sources of Toxoplasma infection in pregnant women: European multicentre case-control study. European Research Network on Congenital Toxoplasmosis. Bmj 321: 142-147.

Dunn D, Wallon M, Peyron F, Petersen E, Peckham C, Gilbert R 1999. Mother-to-child transmission of toxoplasmosis: risk estimates for clinical counselling. Lancet 353: 1829-1833.

Evengard B, Petersson K, Engman ML, Wiklund S, Ivarsson SA, Tear-Fahnehjelm K, Forsgren M, Gilbert R, Malm G 2001. Low incidence of Toxoplasma infection during pregnancy and in newborns in Sweden. Epidemiol Infect 127: 121-127.

Figueiro-Filho EA, Senefonte FR, Lopes AH, de Morais OO, Souza Junior VG, Maia TL, Duarte G 2007. Freqüência das infecções pelo HIV-1, rubéola, sífilis, toxoplasmose, citomegalovírus, herpes simples, hepatite B, hepatite C, doença de Chagas e HTLV I/ II em gestantes do Estado de Mato Grosso do Sul. Rev Soc Bras Med Trop 40: 181-187.

Foulon W, Naessens A, Ho-Yen D 2000. Prevention of congenital toxoplasmosis. J Perinat Med 28: 337-345.

Foulon W, Naessens A, Lauwers S, De Meuter F, Amy JJ 1988. Impact of primary prevention on the incidence of toxoplasmosis during pregnancy. Obstet Gynecol 72: 363-366.

Foulon W, Villena I, Stray-Pedersen B, Decoster A, Lappalainen M, Pinon JM, Jenum PA, Hedman K, Naessens A 1999. Treatment of toxoplasmosis during pregnancy: a multicenter study of impact on fetal transmission and children's sequelae at age 1 year. $A m J$ Obstet Gynecol 180: 410-415.

Gilbert R, Dunn D, Wallon M, Hayde M, Prusa A, Lebech M, Kortbeek T, Peyron F, Pollak A, Petersen E 2001. Ecological comparison of the risks of mother-to-child transmission and clinical manifestations of congenital toxoplasmosis according to prenatal treatment protocol. Epidemiol Infect 127: 113-120.

Gilbert RE, Stanford MR, Jackson H, Holliman RE, Sanders MD 1995. Incidence of acute symptomatic Toxoplasma retinochoroiditis in South London according to country of birth. Bmj 310: 1037-40.

Glasner PD, Silveira C, Kruszon-Moran D, Martins MC, Burnier Junior
M, Silveira S, Camargo ME, Nussenblatt RB, Kaslow RA, Belfort Junior R 1992. An unusually high prevalence of ocular toxoplasmosis in Southern Brazil. Am J Ophthalmol 114: 136-144.

Gras L, Wallon M, Pollak A, Cortina-Borja M, Evengard B, Hayde M, Petersen E, Gilbert R 2005. Association between prenatal treatment and clinical manifestations of congenital toxoplasmosis in infancy: a cohort study in 13 European centres. Acta Paediatr 94: 1721-1731.

Guerina NG, Hsu HW, Meissner HC, Maguire JH, Lynfield R, Stechenberg B, Abroms I, Pasternack MS, Hoff R, Eaton RB, Grady GF. 1994. Neonatal serologic screening and early treatment for congenital Toxoplasma gondii infection. The New England Regional Toxoplasma Working Group. N Engl J Med 330: 1858-1863.

Hohlfeld P, Daffos F, Thulliez P, Aufrant C, Couvreur J, MacAleese J, Descombey D, Forestier F 1989. Fetal toxoplasmosis: outcome of pregnancy and infant follow-up after in utero treatment. J Pediatr 115: 765-769.

Jenum PA, Stray-Pedersen B, Melby KK, Kapperud G, Whitelaw A, Eskild A, Eng J 1998. Incidence of Toxoplasma gondii infection in 35,940 pregnant women in Norway and pregnancy outcome for infected women. J Clin Microbiol 36: 2900-2906.

Jones JL, Lopez A, Wilson M, Schulkin J, Gibbs R 2001. Congenital toxoplasmosis: a review. Obstet Gynecol Surv 56: 296-305.

Kapperud G, Jenum PA, Stray-Pedersen B, Melby KK, Eskild A, Eng J 1996. Risk factors for Toxoplasma gondii infection in pregnancy. Results of a prospective case-control study in Norway. Am J Epidemiol 144: 405-412.

Lago EG, Neto EC, Melamed J, Rucks AP, Presotto C, Coelho JC, Parise C, Vargas PR, Goldbeck AS, Fiori RM 2007. Congenital toxoplasmosis: late pregnancy infections detected by neonatal screening and maternal serological testing at delivery. Paediatr Perinat Epidemiol 21: 525-531.

Lebech M, Andersen O, Christensen NC, Hertel J, Nielsen HE, Peitersen B, Rechnitzer C, Larsen SO, Norgaard-Pedersen B, Petersen E 1999. Feasibility of neonatal screening for Toxoplasma infection in the absence of prenatal treatment. Danish Congenital Toxoplasmosis Study Group. Lancet 353: 1834-1837.

Lebech M, Joynson DH, Seitz HM, Thulliez P, Gilbert RE, Dutton GN, Ovlisen B, Petersen E 1996. Classification system and case definitions of Toxoplasma gondii infection in immunocompetent pregnant women and their congenitally infected offspring. European Research Network on Congenital Toxoplasmosis. Eur J Clin Microbiol Infect Dis 15: 799-805.

Liesenfeld O, Montoya JG, Kinney S, Press C, Remington JS 2001. Effect of testing for IgG avidity in the diagnosis of Toxoplasma gondii infection in pregnant women: experience in a US reference laboratory. J Infect Dis 183: 1248-1253.

Lopez A, Dietz VJ, Wilson M, Navin TR, Jones JL 2000. Preventing congenital toxoplasmosis. MMWR Recomm Rep 49: 59-68.

Mombro M, Perathoner C, Leone A, Nicocia M, Moiraghi Ruggenini A, Zotti C, Lievre MA, Fabris C 1995. Congenital toxoplasmosis: 10-year follow up. Eur J Pediatr 154: 635-639.

Montoya JG, Liesenfeld O 2004. Toxoplasmosis. Lancet 363: 19651976.

Montoya JG, Liesenfeld O, Kinney S, Press C, Remington JS 2002. VIDAS test for avidity of Toxoplasma-specific immunoglobulin $\mathrm{G}$ for confirmatory testing of pregnant women. $J$ Clin Microbiol 40: 2504-2508.

Mozzatto L, Procianoy RS 2003. Incidence of congenital toxoplasmosis in Southern Brazil: a prospective study. Rev Inst Med Trop Sao Paulo 45: 147-151. 
Munoz Batet C, Guardia Llobet C, Juncosa Morros T, Vinas Domenech L, Sierra Soler M, Sanfeliu Sala I, Bosch Mestres J, Dopico Ponte E, Lite Lite J, Matas Andreu L, Juste Sanchez C, Barranco Romeu M 2004. Toxoplasmosis and pregnancy. Multicenter study of 16,362 pregnant women in Barcelona. Med Clin (Barc) 123: 12-16.

Naessens A 2003. Screening for toxoplasmosis during pregnancy: the situation in Belgium. Arch Pediatr 10 (Suppl. 1): 18.

Naessens A, Jenum PA, Pollak A, Decoster A, Lappalainen M, Villena I, Lebech M, Stray-Pedersen B, Hayde M, Pinon JM, Petersen E, Foulon W 1999. Diagnosis of congenital toxoplasmosis in the neonatal period: a multicenter evaluation. J Pediatr 135: 714-719.

Neto EC, Anele E, Rubim R, Brites A, Schulte J, Becker D, Tuuminen T 2000. High prevalence of congenital toxoplasmosis in Brazil estimated in a 3-year prospective neonatal screening study. Int $J$ Epidemiol 29: 941-947.

Nobrega OT, Karnikowski MG 2005. An estimation of the frequency of gestational toxoplasmosis in the Brazilian Federal District. Rev Soc Bras Med Trop 38: 358-360.

Paul M, Petersen E, Szczapa J 2001. Prevalence of congenital Toxoplasma gondii infection among newborns from the Poznan region of Poland: validation of a new combined enzyme immunoassay for Toxoplasma gondii-specific immunoglobulin A and immunoglobulin M antibodies. J Clin Microbiol 39: 1912-1916.
Peyron F, Wallon M, Liou C, Garner P 2000. Treatments for toxoplasmosis in pregnancy. Cochrane Database Syst Rev CD001684.

Remington JS, McLeod R, Thulliez P, Desmonts G 2005. Toxoplasmosis. In JS Remington, JO Klein, Infectious Diseases of the Fetus and Newborn Infant, WB Saunders, Philadelphia, p. 947-1091.

Remington JS, Thulliez P, Montoya JG 2004. Recent developments for diagnosis of toxoplasmosis. J Clin Microbiol 42: 941-945.

Safadi MA, Berezin EN, Farhat CK, Carvalho ES 2003. Clinical presentation and follow up of children with congenital toxoplasmosis in Brazil. Braz J Infect Dis 7: 325-331.

Segundo GR, Silva DA, Mineo JR, Ferreira MS 2004. Congenital toxoplasmosis in Uberlandia, MG, Brazil. J Trop Pediatr 50: 50-53.

Signorell LM, Seitz D, Merkel S, Berger R, Rudin C 2006. Cord blood screening for congenital toxoplasmosis in Northwestern Switzerland, 1982-1999. Pediatr Infect Dis J 25: 123-128.

Thiebaut R, Leproust S, Chene G, Gilbert R 2007. Effectiveness of prenatal treatment for congenital toxoplasmosis: a meta-analysis of individual patients' data. Lancet 369: 115-122.

Varella IS, Wagner MB, Darela AC, Nunes LM, Muller RW 2003. Prevalência de soropositividade para toxoplasmose em gestantes. J Pediatr (Rio J) 79: 69-74. 